\title{
Influence of geometrical boundary conditions on the estimation of rheological parameters
}

\author{
L. Testut, ${ }^{1}$ I. E. Tabagco, ${ }^{2}$ C. Bianchi ${ }^{3}$ F. Rémy ${ }^{1}$ \\ ${ }^{1}$ UMR5566, Groupe de Recherche de Géodésie Spatiale, CNES-CNRS, Toulouse Cedex 31055, France \\ ${ }^{2}$ Dipartimento di Scienze della Terra, Università degli Studi di Milano, I-20129 Milan, Italy \\ ${ }^{3}$ ING, Via di Vigna Murata 605, I-000143 Rome, Italy
}

\begin{abstract}
Improved knowledge of geometrical boundary conditions, such as bedrock geometry and surface topography, can contribute significantly to glaciological studies including ice-sheet-flow modelling. Precise thickness and altimetric data allow an estimation of ice-flow direction, the balance velocity and the basal shear stress. These parameters are calculated along a $1160 \mathrm{~km}$ profile in East Antarctica using a relationship between shear stress, basal temperature, the Glen flow exponent and a parameter related to strain rate. Strong variations of the flow-law parameters and basal conditions are found to play a major role in the ice-flow pattern. Sliding, anisotropy and longitudinal stress strongly perturb the validity of the law, but their signature can be identified.
\end{abstract}

\section{INTRODUCTION}

Topographic maps contain a lot of information about the different phenomena that can affect an ice sheet. At large scale $(>1000 \mathrm{~km})$, ice-sheet size and shape are controlled by climatic and dynamic processes and by boundary conditions. Several processes also act on the medium (100 to $>1000 \mathrm{~km})$ and small scale (1 to $>100 \mathrm{~km}$ ): anisotropy, longitudinal stress, bedrock geometry, basal sliding, etc. Each of these processes has its own effect on the surface of the ice sheet. Due to the precision of satellite altimetry, we are better able to determine the effects of these processes on the surface topography. The problem lies in separating and explaining their different signatures.

Some authors already use the surface topography to estimate rheological parameters (Young and others, 1989; Rémy and others, 1996), but these data alone are not sufficient. One of the major limitations when topography is used to test or constrain flow models is the lack of precise bedrock topography. Recently, during an Italian expedition in Terre Adélie, ice-thickness measurements were performed along a $1200 \mathrm{~km}$ traverse between Terra Nova Bay and Dome Concordia (Dome G) (Fig. 1). The aim of this paper is to develop a classical ice-sheet model and to use precise geometrical boundary data to better understand the ice-flow processes.

\section{DATA}

Ice-thickness data were obtained by radio-echo sounding from an airborne radar of $60 \mathrm{MHz}$ frequency. These data were then combined with an interpolated profile from European Remote-sensing Satellite (ERS-1) altimetry. After smoothing and digitization, a file of bedrock elevation for every $1 \mathrm{~km}$ along the $1160 \mathrm{~km}$ profile was produced, with a mean vertical precision of about $10 \mathrm{~m}$. Comparison of this bedrock profile with the interpolated bedrock from the
Scott Polar Research Institute (SPRI) glaciological and geophysical folio (Drewry and Jordan, 1983) shows large differences at the small scale: in some places the two profiles differ by more than $400 \mathrm{~m}$ (Fig. 2).

The very dense sampling of the geodesic cycle of the ERS-1 altimetric mission allows us to recover the surface topography with a very high spatial resolution. Rémy and others (in press) analysed 30 million waveforms of altimetric data over Antarctica to compute maps on a $1 / 30^{\circ}$

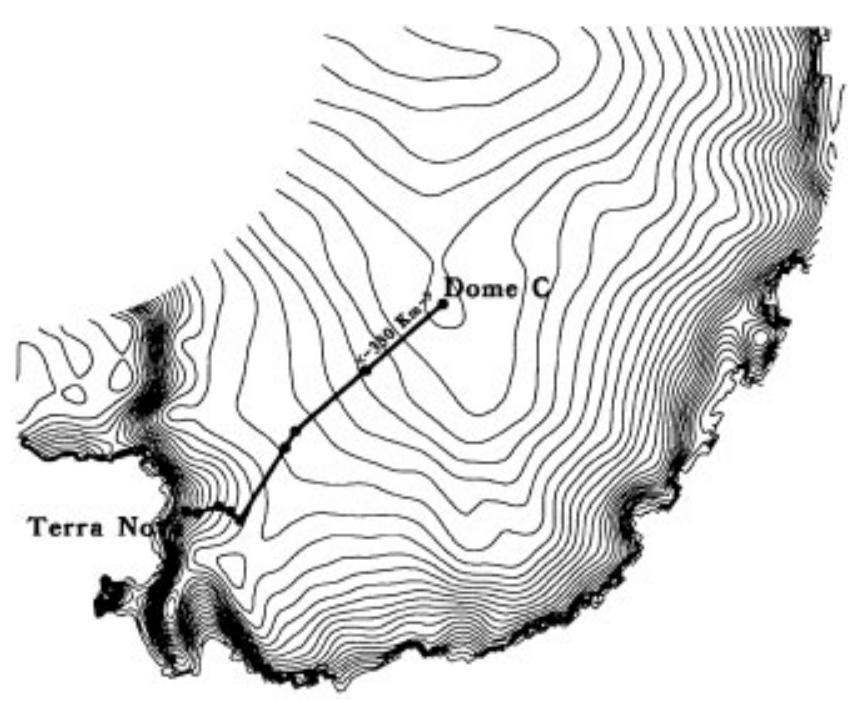

Fig. 1. East Antarctica from $90^{\circ}-180^{\circ} \mathrm{E}$. Contours begin at $82^{\circ} \mathrm{S}$. Contour interval is $130 \mathrm{~m}$. The thick line corresponds to the flight traverse carried out in Fanuary 1997 from the Terra Nova Bay Italian base $\left(164.1^{\circ} \mathrm{E}, 74.69^{\circ} \mathrm{S}\right)$ to Dome $C$ $\left(75.1^{\circ} \mathrm{E}, 123.38^{\circ} \mathrm{S}\right)$. The limits of each leg are indicated by black points. 


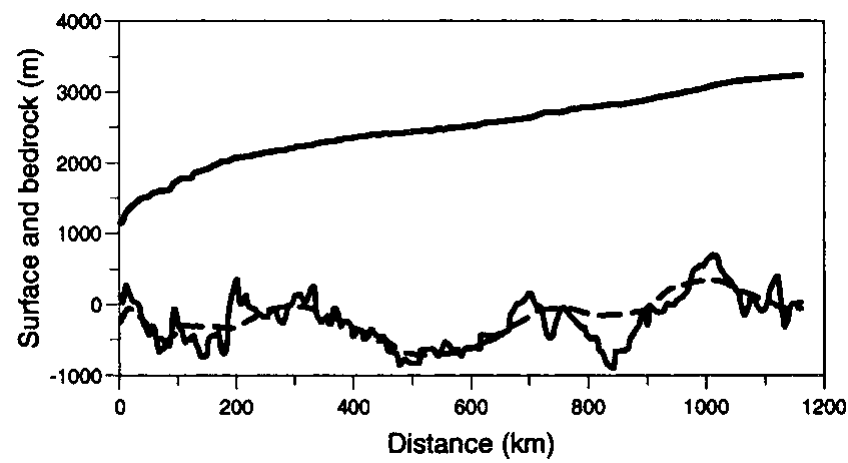

Fig. 2. Surface and bedrock geometry from Terra Nova Bay ( $\mathrm{km} \mathrm{0)}$ to Dome C ( km 1160). Surface is from ERS-1 altimetry. Solid bedrock from traverse radio-echo soundings. The dashed line correspond to the bedrock interpolated from Drewry and Fordan (1983).

grid. The estimated elevation precision of this high-resolution topography is around $30 \mathrm{~cm} \mathrm{rms}$ at crossover points.

We calculate the angle between our profile and the flow direction represented by the local slope (averaged over $10 \mathrm{~km}$ ). The mean value of this angle for the total flight is $20^{\circ}$. The greatest values $\left(>45^{\circ}\right)$ are localized between $\mathrm{km}$ 190 and 350, along the profile this occurs some $200 \mathrm{~km}$ upstream of the $90^{\circ}$ turning of the flight (see Fig. 1). Except for this section, the profile mainly follows the steepest slope direction and the plateau does not exhibit strong convergence or divergence zones.

\section{THEORETIGAL BASIS}

\section{Equations}

We assume the "shallow-ice approximation" and a powercreep law for the behaviour of the ice which gives the depth-averaged deformation velocity, $U_{\mathrm{d}}$, as a function of thickness, $H$, and basal shear stress, $\tau$, to the power $n$. We will use here the analytical expression of Lliboutry (1981):

$$
\begin{aligned}
U_{\mathrm{d}} & =B(T) H \tau^{n} \\
\tau & =\rho g H \alpha \\
B(T) & =\frac{B_{\mathrm{o}} \exp \left[k\left(T_{\mathrm{b}}-T_{\mathrm{m}}\right)\right]}{p+2} .
\end{aligned}
$$

$B(T)$ is the function of how the ice deformation depends on ice temperature via an Arrhenius-type relation with $k=Q / R T_{\mathrm{b}}^{2}$ and $p=n-1+k G H$. Here $G$ is the bottom temperature gradient taken as $0.022^{\circ} \mathrm{Cm}^{-1}$ corresponding to a $50 \mathrm{~mW} \mathrm{~m}{ }^{-2}$ geothermic flux, $T_{\mathrm{b}}$ is the mean bottom temperature, $T_{\mathrm{m}}$ is the melting temperature at the bottom of the ice sheet $\left(T_{\mathrm{m}}=\right.$ $273-H / 1503$ expressed in $\mathrm{K}), Q$ is the activation energy for creep taken as $60 \mathrm{~kJ} \mathrm{~mol}^{-1}, R$ is the universal gas constant $(8.31$ $\left.\mathrm{J} \mathrm{mol}^{-1} \mathrm{~K}^{-1}\right), \rho$ is the density of ice, $g$ is the gravitational constant and $B_{0}$ the flow-law coefficient which seems to depends on crystal structure, orientation of the $c$ axes and impurity concentration.

Lliboutry obtained Equation (3) from an analytical integration of $\mathrm{d} u / \mathrm{d} z$ based on a relation between temperature and depth. The error due to this analytical integration with respect to a numerical integration is less than $1 \%$. The only major assumptions are that the rheological parameters $B_{0}$, $n$ and $Q$ are constant through the ice thickness.
For steady-state flow with neither convergence nor divergence, the balance velocity $U_{\mathrm{b}}$ is given by

$$
U_{\mathrm{b}}=\int_{\text {dome }}^{x} \frac{b \mathrm{~d} x}{H}
$$

where $b$ is the accumulation rate.

Assuming equality of these two velocities we have, from previous equations, a relation between the thickness and the shear stress:

$$
H^{2} \tau^{n}=f
$$

where $f$ is the accumulation integral divided by $B(T)$.

Most models are based on some form of these relations. Although the flow law is well supported by mechanical experiments, its use in models poses a few problems (Alley, 1992). The different parameters $n, B_{\mathrm{o}}$ and $Q$ have a large set of empirical values which can vary with the state of the ice (temperature, viscosity, strain rate, types of creep, etc.). The scale of calculation of the shear stress is also a "parameter" which can have an influence on the validity of the law. In this paper we endeavour to use the precision of our data to estimate these different parameters.

\section{Input values}

Spatial scale for calculating the slope

The surface slope and its direction play a role in estimating the magnitude and direction of ice flow. Due to the presence of undulations at the $10 \mathrm{~km}$ scale, the length of smoothing of the topography is critical. Many authors (Paterson, 1981; Cooper and others 1982; Young and others, 1989) suggest
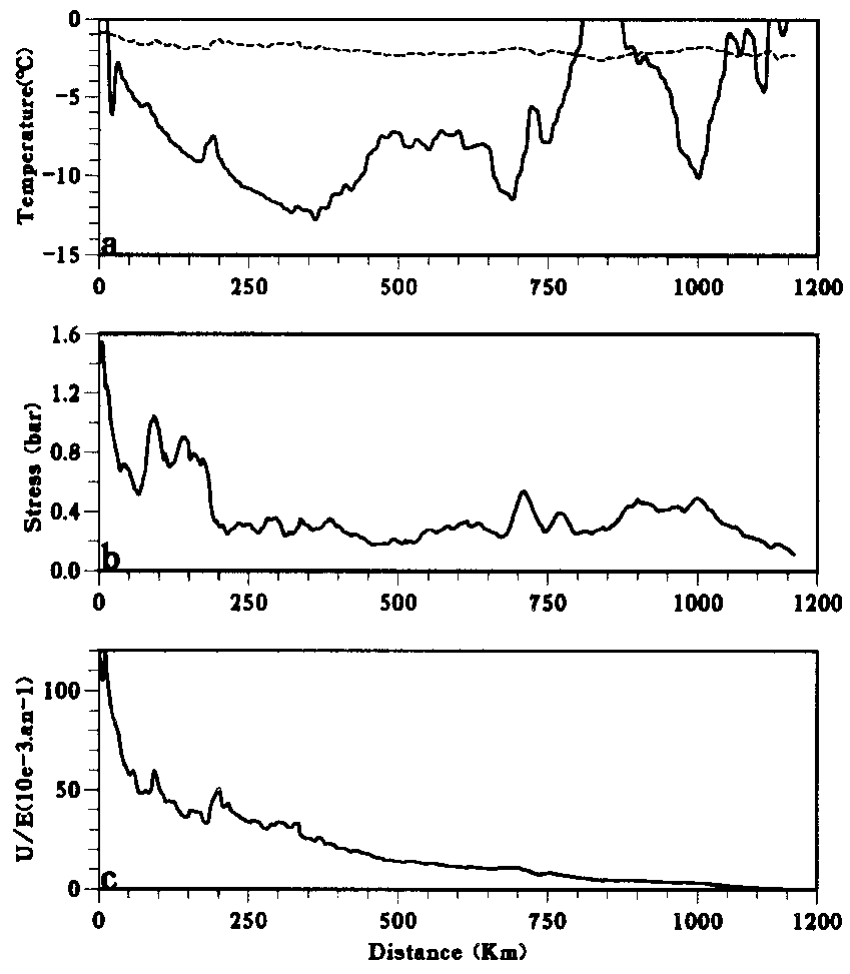

Fig. 3. Quantities involved in the theory from Terra Nova Bay ( $\mathrm{km} \mathrm{0)}$ to Dome C ( km 1160): (a) Basal temperature estimated from the thermodynamic equation (solid line) and the basal melting temperature correction (dashed line); (b) shear stress calculated at a 20 times thickness scale from the ERS-1 geodetic topography; and (c) strain rate calculated from balance velocity and thickness. 
using a $50 \mathrm{~km}$ scale when calculating the shear stress to smooth the effects of the longitudinal stresses. Investigations on the influence of spatial smoothing with our data led to the same result. In this study we will use the surface slope calculated from the ERS-1 altimetric surface by linear regression at each point at a scale of 20 times the thickness. Using this smoothing, Figure $3 \mathrm{~b}$ shows the variation of basal shear stress along the Terra Nova Bay-Dome C profile.

Accumulation rate, basal temperature and shear strain rate Accumulation rates are interpolated along the profile using maps from Radok and others (1987). The bottom temperature (Fig. 3a) is estimated from the thermodynamic equation under a steady-state assumption and considering dissipation, vertical diffusion, vertical and horizontal advection. More details can be found in Ritz (1987), Rémy and others (1996) or Rémy and Minster (1993). The quantity $U / H$ derived from balance velocities and the thickness is supposed to be proportional to the mean shear strain rate $\varepsilon$ through the ice thickness (Fig. 3a). We will use a "temperature-dependent shear strainrate" $\varepsilon^{\prime}=(p+2) U_{\mathrm{b}} / H \exp \left[k\left(T_{\mathrm{b}}-T_{\mathrm{m}}\right)\right]$ in this paper. With this notation the Glen flow law can be written:

$$
\varepsilon^{\prime}=B_{\mathrm{o}} \tau^{n}
$$

\section{ESTIMATION OF THE PARAMETERS}

\section{For a flow law invariable along the profile}

Assuming that the parameters involved in the flow law $(n$, $B_{\mathrm{o}}, Q$, spatial scale of shear-stress calculation, etc.) are constant along the profile, linear regression between $\tau$ and $\varepsilon^{\prime}$ for the whole profile provides a statistical estimation of the parameters $n$ and $B_{\mathrm{o}}$, with $n=1.5$ and $B_{\mathrm{o}}=0.3 \mathrm{bar}^{-1.5} \mathrm{a}^{-1}$ and a correlation coefficient of $r=0.42$. The influence of the $n$ in the $p$ parameter (see Equation (3)) is negligible for the regression. These $n$ and $B_{\mathrm{o}}$ values are consistent with those found in the literature.

We now compare the along-profile variations of the two terms of Equation (5) to examine the validity of our hypothesis and of the flow law with all the parameters (calculated or estimated). Comparison of these two quantities (Fig. 4) shows strong discrepancies. If we focus on the part of the profile which corresponds to the plateau (i.e. after $\mathrm{km} \mathrm{200),} \mathrm{we} \mathrm{see}$

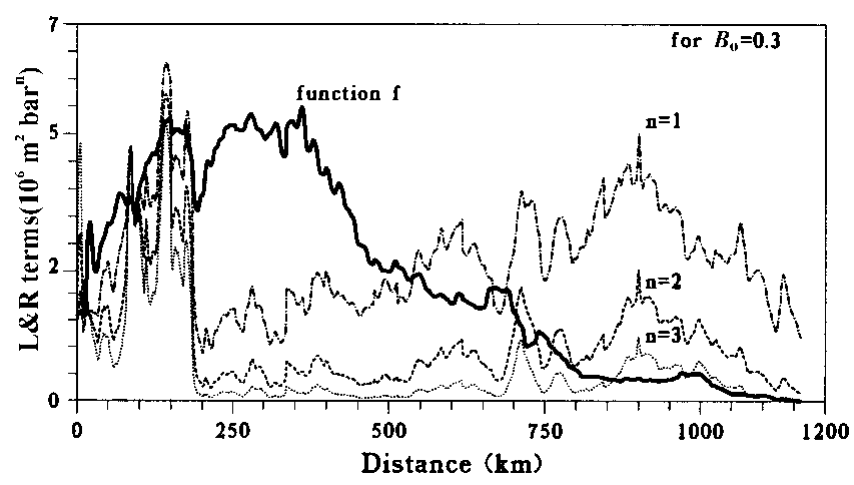

Fig. 4. Comparison of the left and right term of Equation (5) in $10^{6} \mathrm{~m}^{2}$ bar $^{n}$. Solid line corresponds to the righthand term and is equal to the integral of accumulation rate divided by $B(T)$. The three others curves correspond to $H^{2} \tau^{n}$ for $n=1,2$ and 3 , respectively.

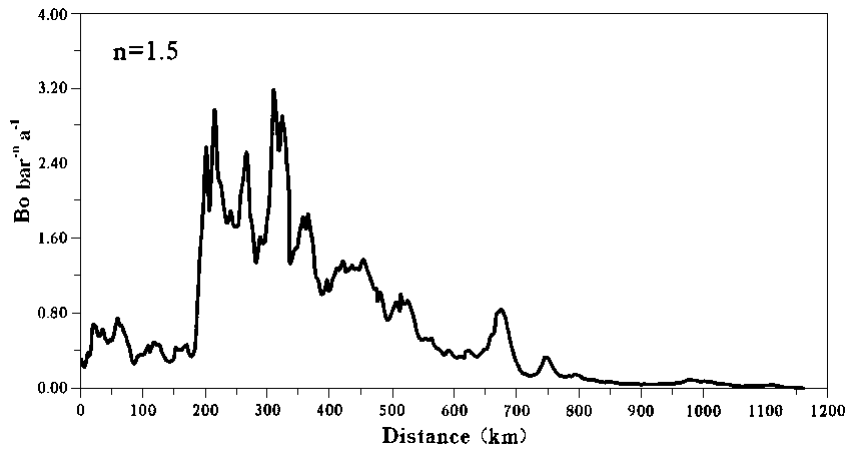
Fig. 5. Magnitude of $B_{\mathrm{o}}\left(\right.$ bar $\left.^{-n} a^{-1}\right)$ needed to satisfy
Equation (5).

that the righthand term decreases slowly up-flow, representing the decreasing value of the accumulation-rate integral. On the contrary, the lefthand term, $H^{2} \tau^{n}$ shows an up-flow trend of either increasing magnitude $(n=1)$ or constant trend $(n=3)$. Any feasible estimation of the accumulation rate, or of the bottom temperature, cannot explain this difference. To explain such discrepancies both a positive bottom temperature from 200 to $>500 \mathrm{~km}$ and a temperature decreasing from $-10^{\circ} \mathrm{C}$ to $-60^{\circ} \mathrm{C}$ from $700-1160 \mathrm{~km}$ would be needed. For the accumulation-rate integral similarly unrealistic values are needed, diminishing by a factor 10 from $\mathrm{km} 900$ (near Dome G) to km 200 (edge of the plateau).

This difference may be explained if the flow-law coefficient $B_{\mathrm{o}}$ has a variation of a factor of 100 and the same global trend as the sum of accumulation rate (see Equation (5) and Fig. 4). It is difficult to asses the evolution of $B_{0}$ along the profile since its behaviour depends on various factors or complex processes (fabric, grain-size, impurities, anisotropy, orientation of the $c$ axes, strain, etc.). However, the largescale trend of $B_{\mathrm{o}}$ is qualitatively in agreement with Pimienta and Duval (1987) who note that as the flow increases, a strongly oriented fabric develops, which in turn enhances the flow. Figure 5 shows the magnitude of $B_{\mathrm{o}}$ required to satisfy Equation (5) (with $n=1.5$ ).

\section{For a flow law which varies with the location}

Figure 6a shows the shear stress, $\tau$, versus the temperaturedependent shear strain rate $\varepsilon^{\prime}$. Values of $n$ and $B_{\mathrm{o}}$ can be calculated from the slope of the points in this plot. Using a linear regression with a $100 \mathrm{~km}$ wide window, the parameters $B_{\mathrm{o}}$ and $n$ were calculated each kilometre from $\mathrm{km} 50$ to $\mathrm{km}$ 1110 (Fig. 7). From these two figures we can see that the observed behaviour of the ice along the $1160 \mathrm{~km}$ long profile is more complicated than can be explained by a constant flow law. In spite of the apparent confusion of points in Figure $6 \mathrm{a}$, some significant features can be observed. Most important is that the flow law seems to be valid over distinct segments. Five separate areas show a consistent value of $n$ (Fig. 7), each of them corresponding to a maximum of correlation. The mean values of $n$ and $B_{\mathrm{o}}$ for each of these intervals with their associated correlation, $r$, are given below.

From 0 to $>150$

From 380 to $>480$

From 745 to $>825$

From 850 to $>910$

From 960 to $>1160$

$$
\begin{array}{ll}
n=0.6 \text { and } B_{\mathrm{o}}=0.58 & r=0.58 \text { (zone } 1) \\
n=1.3 \text { and } B_{\mathrm{O}}=0.88 & r=0.95 \text { (zone } 2) \\
n=1.7 \text { and } B_{\mathrm{o}}=0.2 & r=0.60(\text { zone } 3) \\
n=0.7 \text { and } B_{\mathrm{O}}=0.02 & r=0.92(\text { zone } 4) \\
n=3.3 \text { and } B_{\mathrm{o}}=0.3 & r=0.95 \text { (zone } 5)
\end{array}
$$



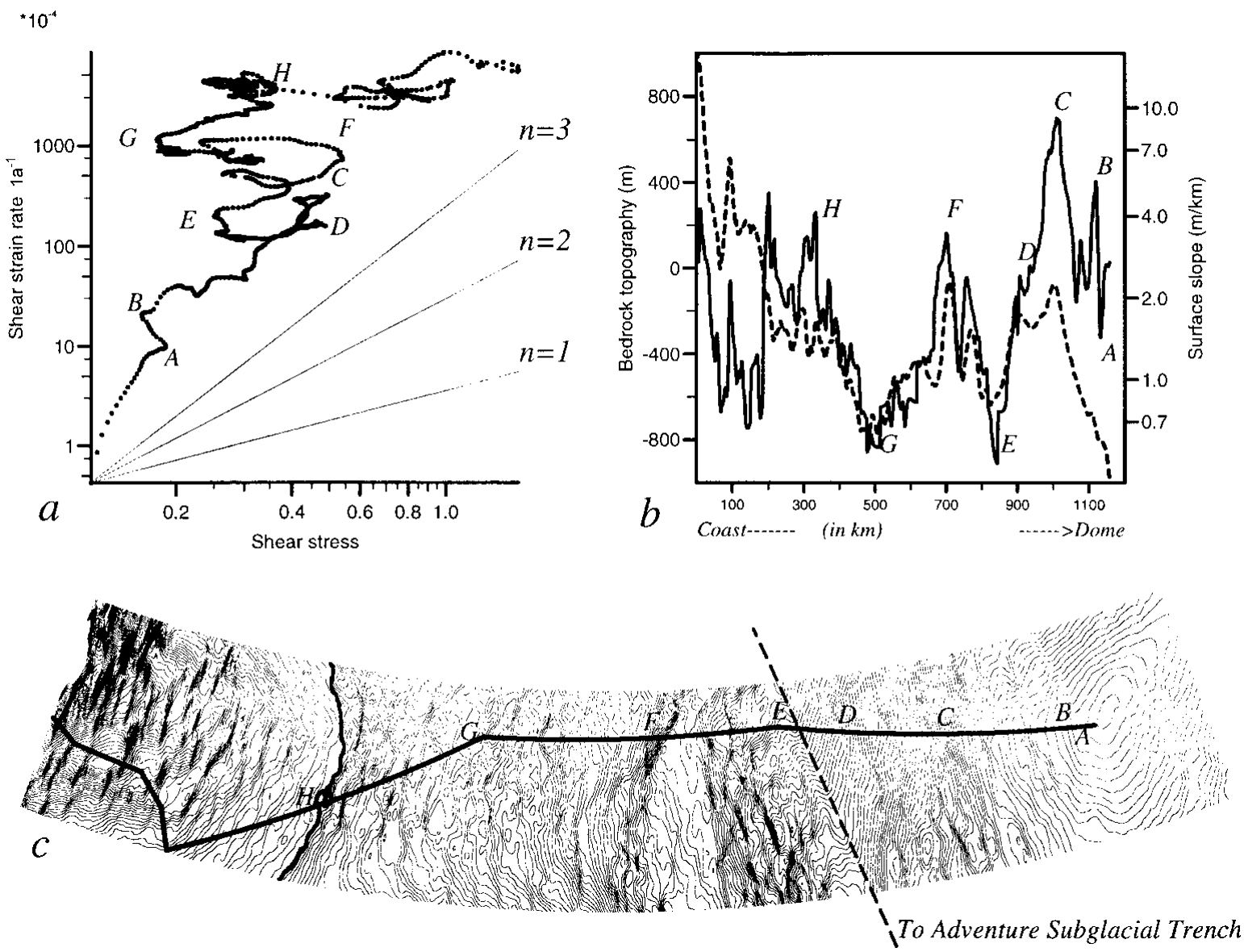

Fig. 6. (a) $\log \tau$ (bar) vs $\log \varepsilon^{\prime}\left(a^{-1}\right)$. (b) Bedrock geometry (solid line) and surface slope (dashed line). (c) Path of the profile on contour elevation map. Below $2300 \mathrm{~m}$ (bold contour) the contours are each $15 \mathrm{~m}$, above $2300 \mathrm{~m}$ contour interval is $5 \mathrm{~m}$.

We consider that the first $350 \mathrm{~km}$ does not fit our hypothesis, because zone 1 is a convergence zone and at the beginning of the plateau the profile from 190 to $350 \mathrm{~km}$ is not aligned in the flow direction.

With the exception of zone 4 (discussed below), the $n$ value seems to increase from the coast to Dome C. Rémy and others (1996) found a value of $n$ around 1 for temperatures less than $-10^{\circ} \mathrm{C}$ and increasing $n$ values for warmer temperatures. One can see from Figures $3 \mathrm{a}$ and 7 that the large-scale behaviour of $n$ and $T_{\mathrm{b}}$ is similar from $\mathrm{km} 200$ to Dome C.

\section{DISGUSSION}

It is obvious from Figure 6 that, even if a classic law can be applied regionally, it is not able to explain all the topographic features observed. However, some of the observed discrepancies can be isolated and explained by local physical phenomena.

\section{Sliding}

Siegert and Ridley (1998), using an analysis of radio-echo sounding, show that the flat-surface region $\left(133^{\circ} \mathrm{E}, 73-74^{\circ} \mathrm{S}\right)$ lying over the Adventure Subglacial Trench had a relatively bright return from the ice substrate, but no mirror-like reflection. They conclude that water is not trapped within a subglacial hollow and infer that the transport of water probably occurs through an unknown basal hydrological system. This is probably the channel that is crossed by our profile at km 850 . This region corresponds to a maximum in thickness $(>3700 \mathrm{~m})$ and should have a positive basal temperature (Fig. 3a). A careful examination of the surface topography of this region (between $\mathrm{D}$ and $\mathrm{E}$ in Fig. 6c) shows a flatter zone. There is also a $10-20 \mathrm{~km}$ wide channel in the topography at the eastern border of the flatter zone which reaches the Adventure Subglacial Trench and could mark the position of the subglacial hydrological system. The occurrence of sliding produces a flatter surface and could explain the strong diminution of $\tau$ (between D and $\mathrm{E}$ in Fig. 6a) and the low value of $n$ in zone 4.

Local sliding could also partly explain the anomalies observed between points $\mathrm{C}$ and $\mathrm{D}$ and between points $\mathrm{F}$ and

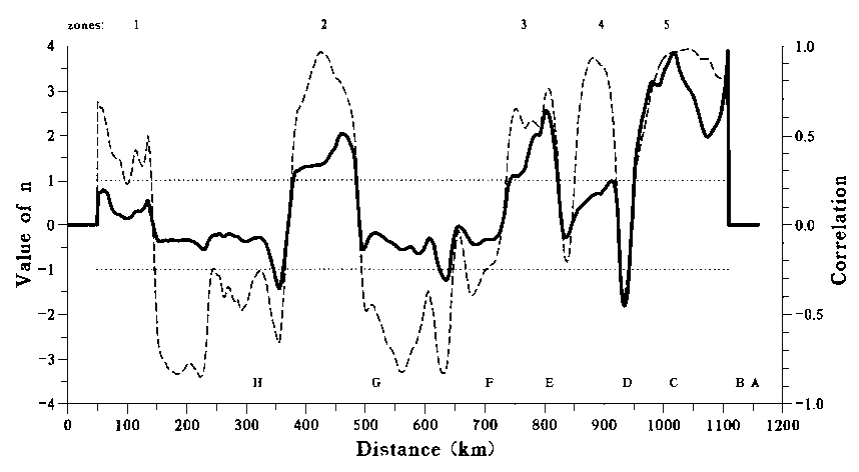

Fig. 7. Linear regression between $\log \tau$ and $\log \varepsilon^{\prime}$ each $\mathrm{km}$ along the profile with a $100 \mathrm{~km}$ window. The solid line corresponds to the Glen flow exponent (i.e. regression coefficient) and the dashed line to the correlation coefficient, $r$, of the regression (right scale). Dotted lines indicate significant correlation at the $99 \%$ confidence level. 
$\mathrm{G}$ where negative values of $n$ are found (Fig. 7). In particular, these anomalies occur when there is a decrease of $\tau$ at constant $\varepsilon^{\prime}$, which seems to correspond to basal sliding (see above between $\mathrm{D}$ and $\mathrm{E}$ ). The presence of relatively high radar-echo reflectivity in both cases (in spite of negative temperature, Fig. 3a) suggests the presence of water at the bottom of the ice. Local phenomena such as enhanced geothermal flux or strain dissipation could generate the right conditions for the existence of water in the ice. This also applies for local anomalies from the flow law in the Dome $\mathrm{C}$ region (for instance in Figure 6a between $\mathrm{km} 1123$ and 1135 where $\tau$ decreases between points A and B). This behaviour could be a consequence of the subglacial channels which occur beneath Dome C (Rémy and Tabacco, 1999).

\section{Anisotropy}

Anisotropy is suggested by Figure 6 a between points $\mathrm{G} \rightarrow \mathrm{H}$ and $\mathrm{E} \rightarrow \mathrm{F}$ (or between zones 2 and 3). At large scale, zones 2 and 3 have the same behaviour with a mean slope around 1.5 but we observe a clear shift between them. Although the ice is subject to shear stress of the same order of magnitude and the temperature is taken into account in $\varepsilon^{\prime}$, these two zones show strong differences in the intensity of the shear strain rate. Changes in the ice-crystal-orientation fabric between these two regions can lead to such behaviour, and correspond to a change of $B_{0}$.

In our case, $B_{\mathrm{o}}$ is enhanced by a factor of 4.4 . Jacka and Budd (1989) found that in isotropic ice the development of anisotropy leads to an enhancement factor of 3 when isotropic ice is subject to compression and a factor 8 in shear. Rémy and others (1996) found an enhancement factor of 3.

\section{Longitudinal stress}

A loop is observed between $\mathrm{km} 650$ and $\mathrm{km} 800$ which perturbs the estimation of $n$ in zone 3 and explains the low value of $r$. This is due to the fact that in this region $\tau$ and $\varepsilon^{\prime}$ vary in a similar way, but with a shift of $20 \mathrm{~km}$. A look at this region on the surface map shows that the profile crosses a flat zone, but the estimation of basal temperature in this region is about $-5^{\circ} \mathrm{C}$, and the depression in the bedrock does not give a strong radar echo. A small trough followed by a bump of $2 \mathrm{~m}$ amplitude is observed at $\mathrm{km} 740$ in the topography. This kind of signature is also observed in the transition zone between strong friction and weak friction in the Lake Vostok area and was quantitatively attributed to the effect of longitudinal stress (Rémy and others, 1999). Therefore, this loop could be a residual effect of longitudinal-stress gradients which have not been entirely smoothed.

\section{CONGLUSION}

The use of a simple model based on the Glen flow law coupled with precise boundary datasets along a $1160 \mathrm{~km}$ profile allowed us: to test the validity of the law; to estimate the variation of the ice-flow parameters; and to link some of the anomalies with physical processes.

The major result is in determining the non-unique nature of the flow law and/or the non-constancy of its rheological parameters along the profile. Assuming a unique law with constant parameters leads to discrepancies which cannot be explained with reasonable assumptions. On the contrary, if the rheological parameters $n$ and $B_{0}$ averaged over a $100 \mathrm{~km}$ scale are assumed to vary freely, $n$ is found to vary discon- tinuously, but on average increases from the coast to Dome C, probably linked to the increase in basal temperature. Moreover, the different physical processes (sliding, anisotropy, longitudinal stress) involved in some of these discrepancies might be isolated by their expected effect on $n$ and $B_{0}$.

A precise knowledge of the geometric flow boundary can contribute significantly to ice-flow modelling via a better constraint of the bottom and surface topography, an estimation of the model parameters, and a better description of the signature of anisotropy, sliding or longitudinal stress. The modelling of these mechanical processes could thus be improved or tested.

\section{AGKNOWLEDGEMENTS}

We thank B. Legrésy for his help and numerous discussion and the two referees for their comments. This paper is the result of a Franco-Italian collaboration, supported by an European Science Foundation (ESF) grant, within the European Ice Sheet Modelling Initiative and it is a contribution to the "European Project for Ice Coring in Antarctica", a joint ESF (European Science Foundation)/European Commission (EC) scientific programme, funded by the EC under the Environment and Climate (1995-98) contract ENV4-CT950074 and by national contributions from Belgium, Denmark, France, Germany, Italy, The Netherlands, Norway, Switzerland and the United Kingdom.

\section{REFERENCES}

Alley, R. B. 1992. Flow-law hypotheses for ice-sheet modeling. f. Glaciol., 38(129), 245-256.

Cooper, A. P. R., N. F. McIntyre and G. de Q. Robin. 1982. Driving stresses in the Antarctic ice sheet. Ann. Glaciol., 3, 59-64.

Drewry, D. J. and J. R. Jordan. 1983. The bedrock surface of Antarctica. In Drewry, D. J., ed. Antarctica: glaciological and geophysical folio. Cambridge, University of Cambridge. Scott Polar Research Institute, Sheet 3.

Jacka, T. H. and W. F. Budd. 1989. Isotropic and anisotropic flow relations for ice dynamics. Ann. Glaciol., 12, 81-84.

Lliboutry, L. 1981. A critical review of analytical approximate solutions for steady state velocities and temperatures in cold ice-sheets. Z. Gletscherkd. Glazialgeol., 15(2), 1979, 135-148.

Paterson, W. S. B. 1981. The physics of glaciers. Second edition. Oxford, etc., Pergamon Press.

Pimienta, P. and P. Duval. 1987. Rate controlling processes in the creep of polar glacier ice. 7. Phys. (Paris), 48, Colloq. C1, 243-248. (Supplément au 3.)

Radok, U., D. Jenssen and B. McInnes. 1987. On the surging potential of polar ice streams. Antarctic surges - a clear and present danger? Boulder, CO, University of Colorado. Cooperative Institute for Research in Environmental Sciences; Melbourne, University of Melbourne. Meteorology Department. (US Department of Energy Report DOE/ER/60197-H1.)

Rémy, F. and J. F. Minster. 1993. Precise altimetric topography in ice-sheet flow studies. Ann. Glaciol., 17, 195-200.

Rémy, F., and I. E. Tabacco. In press. Basal ersoion network near the EPICA ice core site (Dome C, Antarctica). Geophys. Res. Lett.

Rémy, F., C. Ritz and L. Brisset. 1996. Ice-sheet flow features and rheological parameters derived from precise altimetric topography. Ann. Glaciol., 23, 277-283.

Rémy, F., P. Shaeffer and B. Legrésy. 1999. Ice flow physical processes derived from ERS-1 high-resolution map of Antarctica and Greenland ice sheet. Geophys. F. Int., 139, 645-656.

Ritz, C. 1987. Time dependent boundary conditions for calculation of temperature fields in ice sheets. International Association of Hydrological Sciences Publication 170 (Symposium at Vancouver 1987 - The Physical Basis of Ice Sheet Modelling), 207-216.

Siegert, M. J. and J. K. Ridley. 1998. Determining basal ice-sheet conditions in the Dome $\mathrm{C}$ region of East Antarctica using satellite radar altimetry and airborne radio-echo sounding. F. Glaciol., 44(146), 1-8.

Young, N.W., I. D. Goodwin, N. W. J. Hazelton and R. J. Thwaites. 1989. Measured velocities and ice flow in Wilkes Land, Antarctica. Ann. Glaciol., 12, 192-197. 